\title{
Dietary secoisolariciresinol diglucoside and its oligomers with 3-hydroxy- 3-methyl glutaric acid decrease vitamin $E$ levels in rats
}

\author{
Jan Frank ${ }^{1 *}$, Christina Eliasson ${ }^{1}$, Diane Leroy-Nivard ${ }^{1}$, Alicja Budek ${ }^{1}$, Torbjörn Lundh $^{2}$, \\ Bengt Vessby ${ }^{3}$, Per $\AA^{\circ} \operatorname{man}^{1}$ and Afaf Kamal-Eldin ${ }^{1}$ \\ ${ }^{1}$ Department of Food Science, Swedish University of Agricultural Sciences (SLU), Box 7051, S-750 07 Uppsala, Sweden \\ ${ }^{2}$ Department of Animal Nutrition and Management, Swedish University of Agricultural Sciences (SLU), 75007 Uppsala, \\ Sweden \\ ${ }^{3}$ Department of Public Health and Caring Sciences and Unit for Clinical Nutrition Research, Uppsala University, \\ 75125 Uppsala, Sweden
}

(Received 20 October 2003 - Revised 6 February 2004 - Accepted 1 March 2004)

\begin{abstract}
Secoisolariciresinol diglucoside (SDG) is an important dietary lignan that is found at very high levels in flaxseed (1-4\%, w/w). Flaxseed lignans have received much research interest in recent years because of reported phyto-oestrogenic, anticarcinogenic, and anti-atherogenic effects. Previously, flaxseed feeding has been shown to decrease vitamin E concentrations in rats despite the antioxidant potential of SDG in vitro. Sesamin, a sesame lignan, on the other hand has been shown to increase vitamin E concentrations in rats. The aim of the present study was to investigate the effect of dietary SDG and its oligomers on vitamin E and cholesterol concentrations in rats. SDG was extracted from defatted flaxseed flour with a dioxane-ethanol mixture and purified by silica column chromatography. The major oligomers with 3-hydroxy-3-methyl glutaric acid, containing a high ratio of SDG to $p$-coumaric and ferulic acid glucosides, were purified from the extracts by reversed-phase liquid chromatography. When fed to rats at $0.1 \%$ in the diet for $27 \mathrm{~d}$, both SDG and its oligomers had no effect on animal performance but caused an increase in liver cholesterol and a 2-fold reduction in the levels of $\alpha$ - and $\gamma$-tocopherols in rat plasma and liver. It is notable that a phenolic antioxidant, such as SDG, causes a vitamin E-lowering effect in rats. This cannot be explained at present, but warrants further investigations with respect to the magnitude, mechanism, and significance of the observed effect for human nutrition.
\end{abstract}

Flaxseed: Secoisolariciresinol diglucoside: Enterodiol: Vitamin E: Cholesterol

Secoisolariciresinol diglucoside (SDG) is an important dietary lignan that is found at low-to-moderate levels in many plant foods and at very high levels in flaxseed (Linum usitatissimum L.; Axelson et al. 1982; Mazur \& Adlercreutz, 1998). The level of SDG in flaxseed, 1-4\% (w/w) (Johnsson et al. 2000; Eliasson et al. 2003), is 60-700 times higher than that in other edible plant parts (Ford et al. 2001). SDG was isolated from flaxseed for the first time by Bakke \& Klosterman (1956) and was noted to exist in a tan polymeric material that includes among other things 3-hydroxy-3-methyl glutaric acid (HMGA) (Klosterman \& Smith, 1954) and 4-O- $\beta$-D-glucopyranosyl $p$-coumaric acid (linocinnamarin) (Klosterman et al. 1955). 4-O- $\beta$-D-Glucopyranosyl ferulic acid was isolated and identified as one of the main components of the 'flaxseed polymer' (Johnsson et al. 2001). A straightchain oligomeric structure, composed of SDG residues inter-linked by HMGA residues with an average molecular weight of 4000 was assigned to the main lignan of flaxseed
(Ford et al. 2001; Kamal-Eldin et al. 2001). Other lignans reported to be present in flaxseed in much lower quantities include an SDG isomer (Bambagiotti-Alberti et al. 1994a,b), isolariciresinol (Meagher et al. 1999), matairesinol (Mazur \& Adlercreutz, 1998; Meagher et al. 1999; Liggins et al. 2000), and pinoresinol (Meagher et al. 1999; Qui et al. 1999; Sicilia et al. 2003).

Flaxseed lignans have received much research interest in recent years because of reported phyto-oestrogenic, anticarcinogenic, and anti-atherogenic effects (for a review, see Westcott \& Muir, 2000). Ingested SDG is converted by enzymes of the gut microflora into the aglycone, secoisolariciresinol, which is subsequently transformed to the mammalian lignans enterodiol (END) and enterolactone (ENL) (Axelson \& Setchell, 1981; Setchell et al. 1981; Axelson et al. 1982; Borriello et al. 1985). Excretion of these mammalian lignans was found to correlate negatively with the incidence of breast cancer (Adlercreutz et al. 1982, 1986) and SDG has been described as protective

\footnotetext{
Abbreviations: DFF, defatted flaxseed flour; END, enterodiol; ENL, enterolactone; HMGA, 3-hydroxy-3-methyl glutaric acid; SDG, secoisolariciresinol diglucoside.

*Corresponding author: Mr Jan Frank, fax + 46186729 95, email Jan.Frank@1mv.slu.se
} 
against breast, prostate, and colon cancers (Jenab \& Thompson, 1996; Thompson et al. 1996). Flaxseed low in $\alpha$-linolenic acid $(<3 \%)$ was found to reduce atherosclerotic plaques in rabbits (Prasad et al. 1998), and this effect was attributed to the antioxidant and hypocholesterolaemic properties of SDG (Prasad, 1997, 1999). Because of these effects, processes were developed for the extraction and purification of flaxseed SDG (Westcott \& Muir, 1996, 1998) to be incorporated in consumer products (Westcott \& Muir, 2000).

It was previously reported that sesamin, a major lipophilic lignan in sesame seed, lowers cholesterol and elevates $\gamma$-tocopherol levels in rats (Kamal-Eldin et al. 2000). Since this observation, we have screened the effects of various antioxidants including butylated hydroxy toluene, curcumin, (+)-catechin, cyanidin-3-glucoside, ferulic, caffeic and chlorogenic acids for their effects on the levels of cholesterol and tocopherols in rats (Kamal-Eldin et al. 2000; Frank et al. 2002, 2003a,b). The different phenolic compounds showed variable effects ranging from no effect to significant elevating effects on either or both parameters. Despite the beneficial effects of SDG (see earlier), the consumption of flaxseed was found to cause a significant lowering of $\alpha$ - and $\gamma$-tocopherol levels in rats (Ratnayake et al. 1992). In the present study, we isolated SDG and its major oligomers from flaxseed. We then tested their effects on tocopherol and cholesterol levels in a Sprague-Dawley rat model in order to elucidate whether these compounds are responsible for the previously observed effects (Ratnayake et al. 1992) or whether they would spare vitamin E as was previously reported for sesame lignans by our group (Kamal-Eldin et al. 2000).

\section{Materials and methods}

\section{Chemicals and reagents}

SDG and its oligomers (SDG-oligomers) were extracted (as described later) from a flaxseed cake (Alternativ Förädling $\mathrm{AB}$, Glanshammar, Sweden). $o$-Coumaric acid, used as an internal standard in the HPLC analysis of SDG, was purchased from Sigma-Aldrich Chemie (Taufkirchen, Germany). Ethanol was purchased from Kemethyl AB (Haninge, Sweden) and ${ }^{2} \mathrm{H}$-labelled methanol and ${ }^{2} \mathrm{H}_{2} \mathrm{O}$, used for NMR, were purchased from Cambridge Isotope Laboratories Inc. (Andover, MA, USA). The rapeseed oil used in the rat diets was purchased from a local grocery store and the cholesterol, added to these rat diets, was purchased from Sigma Chemical Co. (St Louis, MO, USA). All other solvents and reagents were purchased from E. Merck (Darmstadt, Germany) and were used without further purification.

\section{Extraction and fractionation of flaxseed oligomeric phenols}

Pellets of flaxseed cake were mixed roughly using a kitchen mixer and defatted at room temperature twice with $n$-hexane $(1: 3, \mathrm{w} / \mathrm{v})$, first for $5 \mathrm{~h}$ and then overnight. After drying, the powder was milled to obtain finer particles in a micro-mill (sieve $0.5 \mathrm{~mm}$, speed 1, Retsch type ZM 1; Haan, Germany). This defatted flaxseed flour
(DFF) was extracted at $60^{\circ} \mathrm{C}$ by continuous stirring overnight with $50 \% 1,4$ dioxane-ethanol $(1: 4, \mathrm{v} / \mathrm{v})$. The suspension was filtered and the filtrate was evaporated to dryness in vacuo at $40^{\circ} \mathrm{C}$ to provide the extracts that were used for the purification of SDG-oligomers as described later.

For the separation of SDG-oligomers, $50 \mathrm{~g} \mathrm{C}_{18}$ Bondesil silica ( $40 \mu \mathrm{m}$; Varian Inc., Palo Alto, CA, USA) was packed in Buchner funnels $(50 \mathrm{~mm} \times 70 \mathrm{~mm}$ internal diameter). Two different separations were performed on the same type of column for each of seventeen portions, each corresponding to an extract of $50 \mathrm{~g}$ DFF. First, a pre-washing was performed where a part of the extract was dissolved in methanol $(70 \%, 100 \mathrm{ml})$, loaded on the column, and eluted with methanol $(70 \%, 260 \mathrm{ml})$ to collect the whole oligomeric material. The filtrate was then evaporated in vacuo at $40^{\circ} \mathrm{C}$, re-dissolved in methanol $(50 \%$, $100 \mathrm{ml}$ ) and loaded on a new column for further fractionation. The first effluent was collected as fraction 50A $(100 \mathrm{ml})$ followed by nine other fractions collected separately by elution with: (i) methanol $(50 \%, 3 \times 100 \mathrm{ml})$ to yield fractions 50B, 50C and 50D; (ii) methanol $(60 \%$, $3 \times 100 \mathrm{ml}$ ) to yield fractions $60 \mathrm{~A}, 60 \mathrm{~B}$, and $60 \mathrm{C}$; (iii) methanol $(70 \%, 3 \times 100 \mathrm{ml})$ to yield fractions $70 \mathrm{~A}$, 70B, and 70C. Similar fractions were mixed together depending on their HPLC chromatograms before and after base hydrolysis. For all seventeen separations, the following fractions were mixed together: (i) $50 \mathrm{~B}$ and $50 \mathrm{C}$ forming the mixed fraction $\mathrm{F} 50$; (ii) $60 \mathrm{~B}$ and $60 \mathrm{C}$ forming the mixed fraction F60; (iii) 70A, 70B and 70C forming the mixed fraction F70. The mixed fractions F50, F60 and F70 were analysed by HPLC as whole or in hydrolysed forms. By mixing the F60 and F70 fractions, 7.6 g SDG in the form of oligomeric extracts were available for the rat experiment.

\section{Purification of secoisolariciresinol diglucoside}

DFF $(3 \times 250 \mathrm{~g})$ was used for the separation of pure SDG. Each of the three portions was hydrolysed using aqueous sodium hydroxide $(2 \mathrm{M}, 1$ litre) at room temperature for $19 \mathrm{~h}$. The phenolic glucosides were separated from salt using $40 \mathrm{~g} \mathrm{C}_{18}$ gel (AA12S50; YMC Co., Kyoto, Japan) packed in a Buchner funnel $(35 \mathrm{~mm} \times 70 \mathrm{~mm}$ internal diameter). After conditioning with methanol and thereafter with water, an extract corresponding to $75 \mathrm{~g}$ DFF was loaded on the column, and the salts were washed with water $(50 \mathrm{ml})$ before the phenolic compounds were eluted with methanol. The filtrate was evaporated in vacuo at $40^{\circ} \mathrm{C}$ to dryness, and re-dissolved in chloroform-methanol-water (6:3:1, by vol., $200 \mathrm{ml})$. Portions of this solution $(4 \times 50 \mathrm{ml})$ were loaded separately on a silica gel 60 (0.040-0.063 mm; E. Merck) packed in a glass column $(333 \mathrm{~mm} \times 28 \mathrm{~mm}$ internal diameter), eluted with chloroform-methanol-water (10:5:1, by vol.), and collected in $10 \mathrm{ml}$ tubes. The phenolic content in each tube was assayed by HPLC (see later) and the contents of tubes 50-70 were pooled together to obtain $7 \cdot 3 \mathrm{~g}$ SDG (purity $>95 \%$ by HPLC). 
<smiles>[R]c1cc(/C=C/C(=O)O)ccc1O[C@H]1O[C@H](C(O)O)[C@@H](O)[C@H](O)[C@H]1O</smiles>

(a)

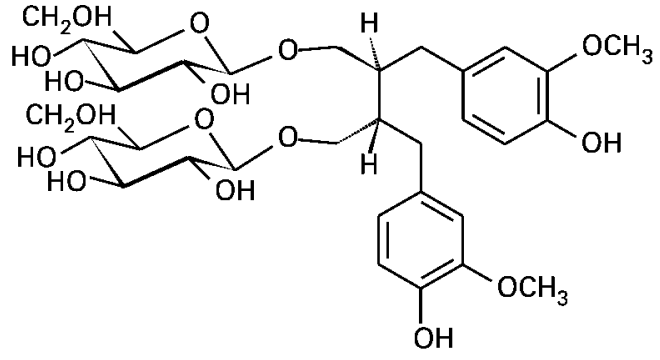

(b)

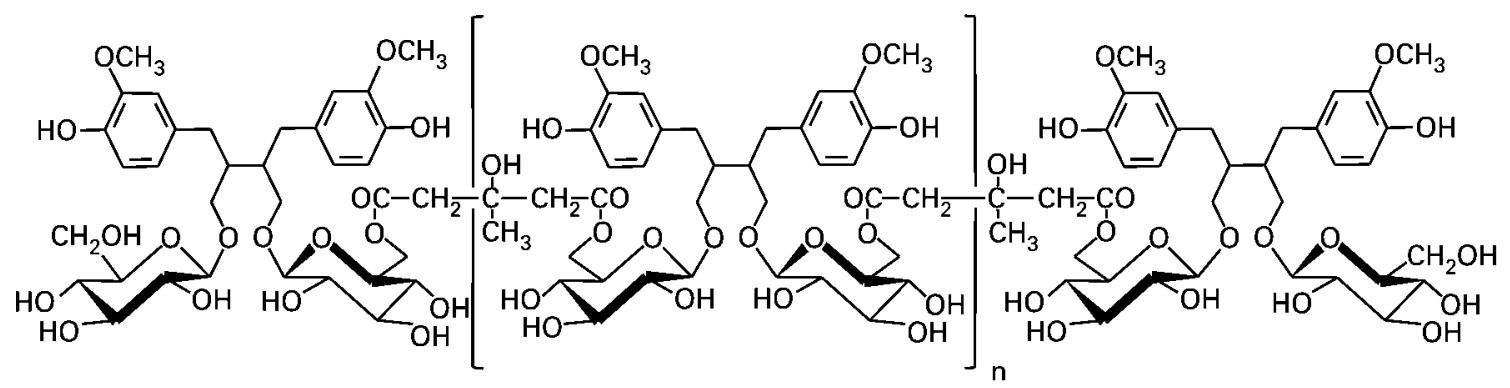

(c)

Fig. 1. Structures of phenolic compounds in flaxseed. (a) $p$-Coumaric acid glucoside, where $\mathrm{R}$ represents $\mathrm{H}$, and ferulic acid glucoside, where $\mathrm{R}$ represents $\mathrm{OCH}_{3}$; (b) secoisolariciresinol diglucoside (SDG); (c) SDG-oligomers (for average oligomers, $n$ is 3).

$p$-coumaric and ferulic acid glucosides, also seem to exist in esterified forms of as yet unidentified structure(s). SDG exists in flaxseed in the form of straight-chain oligomers with HMGA (Ford et al. 2001; Kamal-Eldin et al. 2001). When analysed by HPLC, three fractions (F50, F60, and F70) eluted with peak maxima at 19.6, 22.2 and $23.6 \mathrm{~min}$ compared with the peak maximum at $22.3 \mathrm{~min}$ for the whole oligomeric extract (Fig. 2). The relative ratios of oligomers in the different fractions, calculated using the relative peak areas, were about $64 \%$ (60\% fraction), about $21 \%$ (70\% fraction), and about $15 \%$

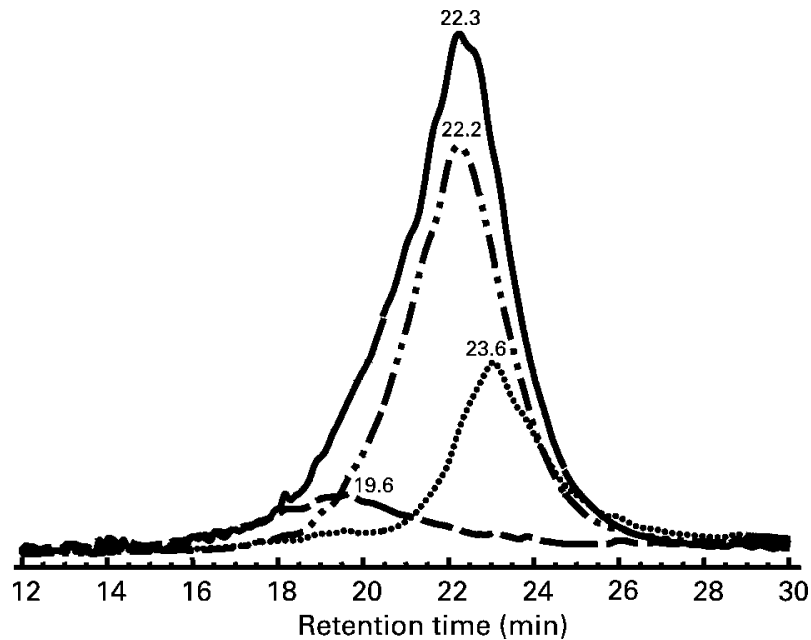

Fig. 2. HPLC chromatograms of the whole extract before fractionation (-) and of the F50 (--), F60 (-.-), and F70 ( ..) mixed oligomeric fractions recorded at $280 \mathrm{~nm}$ (the retention times are shown adjacent to the peaks). For details of the fractions, see p. 170.
(50\% fraction). The chromatogram of F60 was the most similar to that of the whole extract in agreement with the fact that it is the largest fraction (Fig. 2). The ${ }^{1} \mathrm{H}$ NMR spectra of F50, F60, and F70 (not shown) were similar to those obtained previously (Kamal-Eldin et al. 2001) showing that F60 and F70 have a rather similar composition, while F50 has proportionally less SDG and more hydroxycinnamate derivatives. These findings were confirmed by HPLC analysis of the hydrolysed fractions (Fig. 3). Peaks at retention times $13 \cdot 1,15 \cdot 0$, and $20 \cdot 9$ min were assigned
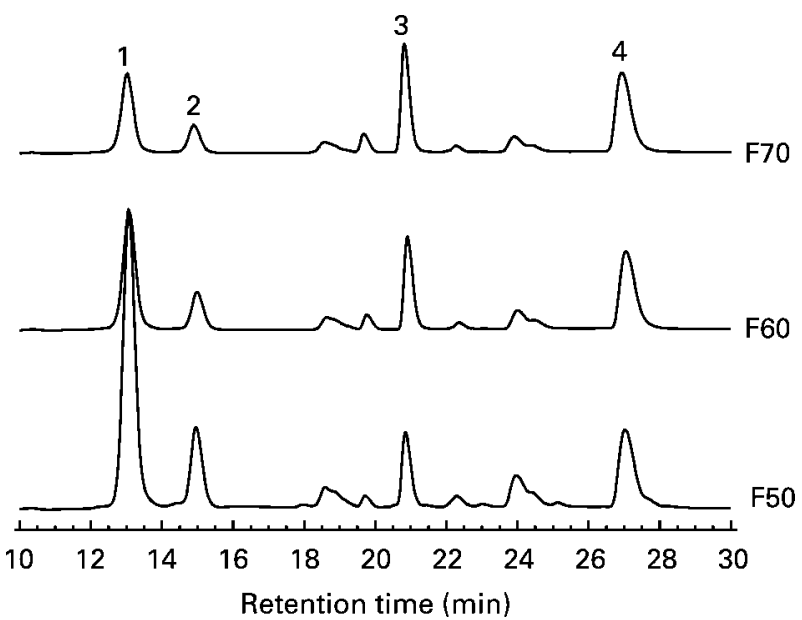

Fig. 3. HPLC chromatograms of the hydrolysed F50, F60, and F70 fractions recorded at $280 \mathrm{~nm}$. Peak 1 corresponds to $p$-coumaric acid glucoside, peak 2 corresponds to ferulic acid glucoside, peak 3 corresponds to secoisolariciresinol diglucoside, and peak 4 corresponds to o-coumaric acid (internal standard). For details of the fractions, see p. 170. 
Table 2. Total and relative amounts of secoisolariciresinol diglucoside (SDG), p-coumaric acid glucoside, and ferulic acid glucoside in the mixed oligomeric fractions*

\begin{tabular}{|c|c|c|c|c|c|c|c|}
\hline & \multicolumn{2}{|c|}{ F50 } & \multicolumn{2}{|c|}{ F60 } & \multicolumn{2}{|c|}{ F70 } & \multirow[b]{2}{*}{ Total (g) } \\
\hline & $g$ & $\% \dagger$ & $g$ & $\% †$ & $g$ & $\% †$ & \\
\hline SDG & 0.4 & 51 & 4.9 & 74 & $2 \cdot 8$ & 83 & $8 \cdot 1$ \\
\hline p-Coumaric acid glucoside & 0.3 & 34 & $1 \cdot 2$ & 18 & 0.4 & 11 & 1.9 \\
\hline Ferulic acid glucoside & 0.1 & 15 & $0 . \overline{6}$ & 8 & 0.2 & 6 & 0.9 \\
\hline Total & 0.8 & & 6.7 & & 3.4 & & $10 \cdot 9$ \\
\hline
\end{tabular}

* The F50, F60, and F70 fractions were isolated from $850 \mathrm{~g}$ defatted flaxseed flour (see p. 170).

†The relative ratios of the compounds in each fraction are shown.

to $p$-coumaric acid glucoside, ferulic acid glucoside, and SDG, respectively (Johnsson et al. 2001). The amounts and relative levels of these three identified compounds were quantified using $o$-coumaric acid as the internal standard and are shown in Table 2.

Three groups of Sprague-Dawley rats were fed a control diet, or diets containing $0.1 \%$ SDG in free form, or in the form of oligomers. The rats received a high dose of SDG ranging from $175 \mathrm{mg} / \mathrm{kg}$ body weight per $\mathrm{d}$ at the beginning of the experiment to $80 \mathrm{mg} / \mathrm{kg}$ body weight per $\mathrm{d}$ before killing, which is still lower than doses of other phenolic compounds fed previously (Kamal-Eldin et al. 2000; Frank et al. 2002, 2003a,b). For man, if a $70 \mathrm{~kg}$ individual ate $10 \mathrm{~g}$ flaxseed, this would correspond to an intake of about $3 \mathrm{mg} \mathrm{SDG} / \mathrm{kg}$ body weight. The high doses used in our experiments were chosen to provoke and detect possible physiological reactions. The present experiment showed no differences between groups in feed intake, animal body weight (about $220 \mathrm{~g}$ ), or liver weight (about $10 \mathrm{~g}$ ) at the end of the experiment.

Feeding SDG and its oligomers had no significant effect on plasma triacylglycerols and cholesterol but caused a slight but significant elevation $(P<0.05)$ of liver cholesterol and of the percentage of cholesterol in the liver lipids (Table 3 ). These present findings are in contradiction with previous reports on the hypocholesterolaemic effects of SDG (Prasad, 1999). Furthermore, HMGA was mentioned to inhibit cholesterol synthesis in non-insulin-dependent diabetics (Laurenti et al. 1990) but there was no difference in cholesterol concentrations between rats eating SDG or the HMGA-interlinked SDG-oligomers in the present study.

Table 4 shows that the feeding of SDG and its oligomers caused a 2-fold lowering of $\alpha$ - and $\gamma$-tocopherols in rat plasma and liver $(P<0.0001)$. Previously, Ratnayake et al. (1992) reported that feeding 10,20 , or $40 \%$ of whole flaxseed in the diet caused a dose-dependent decrease in both $\alpha$ - and $\gamma$-tocopherols in the liver, heart, and spleen of rats. The present results are the first evidence that SDG may be at least one component responsible for this adverse effect of dietary flaxseed. The fact that SDG and its oligomers caused the same magnitude of effect indicates that the other phenolic compounds present in the oligomers, i.e. $p$ coumaric and ferulic acid glucosides, have negligible contribution to this effect. This is in agreement with our previous experiments showing that the feeding of ferulic acid had no effect on $\alpha$ - and $\gamma$-tocopherol levels in rat plasma and liver (Kamal-Eldin et al. 2000; Frank et al. 2003a). Considering its structure, SDG should behave as an antioxidant in a comparable way to ferulic acid. Both compounds contain a methoxy group and an alkyl substituent at ortho and para positions of the phenolic group, respectively, but the presence of the double-bond extending ring conjugation and the carboxylic group in ferulic acid may cause some differences in activity (Wright et al. 2001; Nenadis et al. 2003). However, questions about the physiological activity of dietary phenolic compounds in vivo should take into account aspects related to absorption, metabolism, and bioavailability. Dietary SDG is largely converted to END and ENL, by the intestinal microflora,

Table 3. Effects of secoisolariciresinol diglucoside (SDG) and its oligomers on cholesterol levels in rat plasma and liver

(Mean values and standard deviations for eight rats per group)

\begin{tabular}{|c|c|c|c|c|c|c|c|}
\hline & \multicolumn{2}{|c|}{ Control } & \multicolumn{2}{|c|}{ SDG } & \multicolumn{2}{|c|}{ SDG-oligomers } & \multirow[b]{2}{*}{$P$} \\
\hline & Mean & SD & Mean & SD & Mean & SD & \\
\hline \multicolumn{8}{|l|}{ Plasma } \\
\hline Total cholesterol $(\mathrm{mmol} / \mathrm{l})$ & $2 \cdot 0$ & 0.4 & $2 \cdot 1$ & 0.4 & $2 \cdot 0$ & 0.4 & NS \\
\hline VLDL-+LDL-cholesterol (mmol/l) & 1.2 & 0.4 & $1 \cdot 2$ & 0.2 & 1.3 & 0.4 & NS \\
\hline HDL-cholesterol $(\mathrm{mmol} / \mathrm{l})$ & $0.8^{\mathrm{a}, \mathrm{b}}$ & 0.2 & $0.9^{\mathrm{a}}$ & 0.2 & $0.7^{\mathrm{b}}$ & $0 \cdot 1$ & $<0.05$ \\
\hline HDL-/total cholesterol & 0.43 & 0.10 & 0.46 & 0.60 & 0.38 & 0.80 & NS \\
\hline Triacylglycerols $(\mathrm{mmol} / \mathrm{l})$ & 1.5 & 0.4 & 1.3 & 0.3 & 1.2 & 0.3 & NS \\
\hline \multicolumn{8}{|l|}{ Liver } \\
\hline Total cholesterol $(\mathrm{mg} / \mathrm{g})$ & $16 \cdot 5^{\mathrm{a}}$ & $2 \cdot 8$ & $20 \cdot 4^{\mathrm{b}}$ & 3.2 & $19 \cdot 3^{\mathrm{a}, \mathrm{b}}$ & 4.2 & $<0.05$ \\
\hline Percentage cholesterol in liver lipids & $17 \cdot 4^{\mathrm{a}}$ & $2 \cdot 0$ & $19 \cdot 8^{\mathrm{b}}$ & $2 \cdot 1$ & $20.0^{\mathrm{b}}$ & $2 \cdot 1$ & $<0.05$ \\
\hline
\end{tabular}

a, b Mean values within a row with unlike superscript letters were significantly different. 
Table 4. The effects of secoisolariciresinol diglucoside (SDG) and its oligomers on tocopherol (T) levels in rat plasma and liver (Mean values and standard deviations for eight rats per group)

\begin{tabular}{|c|c|c|c|c|c|c|c|}
\hline & \multicolumn{2}{|c|}{ Control } & \multicolumn{2}{|c|}{ SDG } & \multicolumn{2}{|c|}{ SDG-oligomers } & \multirow[b]{2}{*}{$P$} \\
\hline & Mean & SD & Mean & SD & Mean & SD & \\
\hline \multicolumn{8}{|l|}{ Plasma } \\
\hline$\alpha-\mathrm{T}(\mu \mathrm{mol} / \mathrm{l})$ & $8 \cdot 8^{\mathrm{a}}$ & 1.64 & $5 \cdot 2^{\mathrm{b} *}$ & 0.63 & $4 \cdot 2^{\mathrm{c} *}$ & 0.56 & $<0.01$ \\
\hline$\gamma-\mathrm{T}(\mu \mathrm{mol} / \mathrm{l})$ & $1 \cdot 2^{\mathrm{a}}$ & 0.42 & $0.7^{\mathrm{b}}$ & 0.25 & $0.6^{\mathrm{b}}$ & 0.21 & $<0.005$ \\
\hline$\alpha-\mathrm{T}+\gamma-\mathrm{T}(\mu \mathrm{mol} / \mathrm{l})$ & $10^{a}$ & 2.01 & $5 \cdot 8^{\mathrm{b}_{*}}$ & 0.85 & $4 \cdot 8^{\mathrm{C} *}$ & 0.74 & $<0.05$ \\
\hline$\gamma-T / \alpha-T$ & 0.14 & 0.03 & 0.13 & 0.03 & 0.14 & 0.04 & NS \\
\hline \multicolumn{8}{|l|}{ Liver } \\
\hline$\alpha-\mathrm{T}(\mathrm{nmol} / \mathrm{g})$ & $16 \cdot 1^{\mathrm{a}}$ & $1 \cdot 11$ & $8 \cdot 6^{\mathrm{b}}$ & 0.95 & $7 \cdot 8^{\mathrm{b}}$ & 1.04 & $<0.0001$ \\
\hline$\gamma-\mathrm{T}(\mathrm{nmol} / \mathrm{g})$ & $3 \cdot 1^{\mathrm{a}}$ & 0.62 & $1.5^{\mathrm{b}}$ & 0.37 & $1.3^{\mathrm{b}}$ & 0.42 & $<0.0001$ \\
\hline$\alpha-\mathrm{T}+\gamma-\mathrm{T}(\mathrm{nmol} / \mathrm{g})$ & $19 \cdot 2^{a}$ & 1.44 & $10 \cdot 1^{\mathrm{b}}$ & 0.87 & $9 \cdot 1^{\mathrm{b}}$ & 0.92 & $<0.0001$ \\
\hline$\gamma-T / \alpha-T$ & 0.19 & 0.04 & 0.18 & 0.06 & 0.17 & 0.07 & NS \\
\hline
\end{tabular}

${ }^{a, b, c}$ Mean values within a row with unlike superscript letters were significantly different.

* Mean value was significantly different from control $(P<0.0001)$.

before absorption and only very low concentrations of secoisolariciresinol have been detected in rat and human plasma (Axelson \& Setchell, 1981; Setchell et al. 1981; Axelson et al. 1982; Borriello et al. 1985). Since the phenolic rings of END and ENL are only substituted at the meta position, they would be expected to have negligible antioxidant activity (Wright et al. 2001).

One study in rats (Rickard \& Thompson, 1998) showed that $>50 \%$ of an oral dose of SDG was excreted in the faeces and about $30 \%$ was excreted in the urine $48 \mathrm{~h}$ after ingestion and that the tissues with the highest concentrations of lignan metabolites are those involved in metabolism (i.e. intestine, liver, and kidney). A metabolic study in human volunteers (Nesbitt et al. 1999) showed that END was the mammalian lignan produced in greater quantity and that END:ENL varied greatly among individuals. Incubation of END and ENL with hepatic microsomes in vitro (Jacobs \& Metzler, 1999; Niemeyer \& Metzler, 2002) has shown that both mammalian lignans undergo oxidative metabolism by cytochrome $\mathrm{P} 450$ to produce metabolites carrying one additional hydroxy group at an aliphatic or an aromatic position. The major metabolic route of both lignans under the action of hepatic microsomes from rats, pigs, and especially man involves hydroxylation at aliphatic positions. It is not known to what extent this type of metabolism occurs in vivo, and whether it relates to the results obtained in the present study.

To our knowledge, a lowering effect on vitamin E levels has not been reported for a phenolic compound before. Phenolic antioxidants may increase body vitamin E levels by different mechanisms, for example, by sparing the antioxidant by synergising its scavenging effects on radicals, by recycling of its tocopheroxyl radicals, by inhibiting vitamin $\mathrm{E}$ metabolism, by enhancing vitamin $\mathrm{E}$ absorption, or by inducing antioxidant enzyme systems such as catalase or glutathione peroxidase. The sesame lignan sesamin increased $\gamma$-tocopherol levels in rats through an inhibitory effect on the major cytochrome P450 isozyme(s) involved in vitamin E metabolism (Sontag \& Parker, 2002). On the other hand, the metabolism of certain xenobiotics may increase the rate of free radical generation causing oxidative stress in the liver (Gurbay et al. 2001), which might lead to a reduction in vitamin E levels. For example, it was recently shown that $\beta$-carotene caused a 2 - to 15 -fold induction of certain cytochrome P450 isozymes in Sprague-Dawley rats resulting in the excessive production of reactive oxygen species (Paolini et al. 2001). The significant vitamin E-lowering effect observed for SDG in the present study was not expected, especially with regard to the anticarcinogenic and anti-atherogenic effects reported for flaxseed and its lignans, and cannot be explained at present. Reduced levels of vitamin $\mathrm{E}$, and especially of $\gamma$-tocopherol, have been associated with an increased risk for cardiovascular disease (for a review, see Hensley et al. 2004). Therefore, the present results warrant further investigation with respect to the magnitude, mechanism, and significance of the observed effect for human nutrition before SDG can be considered for supplementation in functional foods. Moreover, investigations on the metabolism of dietary SDG might contribute to the understanding of the findings reported here.

\section{Acknowledgements}

The present study was financed by FORMAS (Swedish Research Council for the Environment, Agricultural Sciences and Spatial Planning).

\section{References}

Adlercreutz H, Fotsis T, Bannwart C, Wahala K, Makela T, Brunow G \& Hase T (1986) Determination of urinary lignans and phytoestrogen metabolites, potential antiestrogens and anticarcinogens, in urine of women on various habitual diets. J Steroid Biochem 25, 791-797.

Adlercreutz H, Fotsis T, Heikkinen R, Dwyer JT, Woods M, Goldin BR \& Gorbach SL (1982) Excretion of the lignans enterolactone and enterodiol and of equol in omnivorous and vegetarian postmenopausal women and in women with breast cancer. Lancet ii, 1295-1299.

Axelson M \& Setchell KD (1981) The excretion of lignans in rats - evidence for an intestinal bacterial source for this new group of compounds. FEBS Lett 123, 337-342.

Axelson M, Sjovall J, Gustafsson BE \& Setchell KD (1982) 
Origin of lignans in mammals and identification of a precursor from plants. Nature 298, 659-660.

Bakke JE \& Klosterman HJ (1956) A new diglucoside from flaxseed. Proc North Dakota Acad Sci 10, 18-22.

Bambagiotti-Alberti M, Coran SA, Ghiara C, Giannellini V \& Raffaelli A (1994a) Revealing the mammalian lignan precursor secoisolariciresinol diglucoside in flax seed by ionspray mass spectrometry. Rapid Commun Mass Spectrom 8, 595-598.

Bambagiotti-Alberti M, Coron SA, Ghiara C, Moreti G \& Raffaelli A (1994b) Investigation of mammalian lignan precursors in flax seed: first evidence of secoisolariciresinol diglucoside in two isomeric forms by liquid chromatograph/mass spectrometry. Rapid Commun Mass Spectrom 8, 929-932.

Borriello SP, Setchell KD, Axelson M \& Lawson AM (1985) Production and metabolism of lignans by the human faecal flora. $J$ Appl Bacteriol 58, 37-43.

Eliasson C, Kamal-Eldin A, Andersson R \& Åman P (2003) HPLC analysis of secoisolariciresinol diglucoside and hydroxycinnamic acid glucosides in flaxseed by alkaline extraction. $J$ Chromatogr 1012A 151-159.

Ford JD, Huang KS, Wang HB, Davin LB \& Lewis NG (2001) Biosynthetic pathway to the cancer chemopreventive secoisolariciresinol diglucoside-hydroxymethyl glutaryl ester-linked lignan oligomers in flax (Linum usitatissimum) seed. $J$ Nat Prod 64, 1388-1397.

Frank J, Kamal-Eldin A, Lundh T, Määttä K, Törrönen R \& Vessby B (2002) Effects of dietary anthocyanins on tocopherols and lipids in rats. J Agric Food Chem 50, 7226-7230.

Frank J, Kamal-Eldin A, Razdan A, Lundh T \& Vessby B (2003a) The dietary hydroxycinnamate caffeic acid and its conjugate chlorogenic acid increase vitamin $\mathrm{E}$ and cholesterol concentrations in Sprague-Dawley rats. J Agric Food Chem 51, $2526-2531$.

Frank J, Lundh T, Parker RS, Swanson JE, Vessby B \& KamalEldin A (2003b) Dietary (+)-catechin and BHT markedly increase alpha-tocopherol concentrations in rats by a tocopherol-omega-hydroxylase-independent mechanism. $J$ Nutr 133, 3195-3199.

Gurbay A, Gonthier B, Daveloose D, Favier A \& Hincal F (2001) Microsomal metabolism of ciprofloxacin generates free radicals. Free Radic Biol Med 30, 1118-1121.

Hara A \& Radin NS (1978) Lipid extraction of tissues with a lowtoxicity solvent. Anal Biochem 90, 420-426.

Hensley K, Benaksas EJ, Bolli R, et al. (2004) New perspectives on vitamin E: gamma-tocopherol and carboxyethylhydroxychroman metabolites in biology and medicine. Free Radic Biol Med 36, 1-15.

Jacobs E \& Metzler M (1999) Oxidative metabolism of the mammalian lignans enterolactone and enterodiol by rat, pig, and human liver microsomes. J Agric Food Chem 47, 1071-1077.

Jenab M \& Thompson LU (1996) The influence of flaxseed and lignans on colon carcinogenesis and beta-glucuronidase activity. Carcinogenesis 17, 1343-1348.

Johnsson P, Kamal-Eldin A, Lundgren LN \& Aman P (2000) HPLC method for analysis of secoisolariciresinol diglucoside in flaxseeds. J Agric Food Chem 48, 5216-5219.

Johnsson P, Peerlkamp N, Kamal-Eldin A, Andersson RE, Andersson R, Lundgren LN \& Åman P (2001) Polymeric fractions containing phenol glucosides in flaxseed. Food Chem 76, 207-212.

Kamal-Eldin A, Frank J, Razdan A, Tengblad S, Basu S \& Vessby B (2000) Effects of dietary phenolic compounds on tocopherol, cholesterol, and fatty acids in rats. Lipids $\mathbf{3 5}$, 427-435.

Kamal-Eldin A, Peerlkamp N, Johnsson P, Andersson R, Andersson RE, Lundgren LN \& Aman P (2001) An oligomer from flaxseed composed of secoisolariciresinoldiglucoside and 3-hydroxy-3-methyl glutaric acid residues. Phytochemistry $\mathbf{5 8}$ 587-590.

Klosterman HJ \& Smith F (1954) The isolation of $\beta$-hydroxy- $\beta$ methylglutaric acid from the seed of flax (Linum usitatissimum). J Am Chem Soc 76, 1229-1230.

Klosterman HJ, Smith F \& Clagett CO (1955) The constitution of linocinnamarin. $J$ Am Chem Soc 77, 420-421.

Laurenti O, Albi F, Artini M, Bravi C, Hurd R \& Demattia G (1990) Effects of HMGA in non-insulin-dependent diabetics with secondary dyslipidemia. Clin Trials $J$ 27, 149-154.

Liggins J, Grimwood R \& Bingham SA (2000) Extraction and quantification of lignan phytoestrogens in food and human samples. Anal Biochem 287, 102-109.

Mazur W \& Adlercreutz H (1998) Natural and anthropogenic environmental oestrogens: the scientific basis for risk assessment. Naturally occuring oestrogens in food. Pure Appl Chem 70, 1759-1776.

Meagher LP, Beecher GR, Flanagan VP \& Li BW (1999) Isolation and characterization of the lignans, isolariciresinol and pinoresinol, in flaxseed meal. J Agric Food Chem 47, $3173-3180$.

Nenadis N, Zhang HY \& Tsimidou MZ (2003) Structure-antioxidant activity relationship of ferulic acid derivatives: effect of carbon side chain characteristic groups. J Agric Food Chem 51, 1874-1879.

Nesbitt PD, Lam Y \& Thompson LU (1999) Human metabolism of mammalian lignan precursors in raw and processed flaxseed. Am J Clin Nutr 69, 549-555.

Niemeyer HB \& Metzler M (2002) Oxidative metabolites and genotoxic potential of mammalian and plant lignans in vitro. J Chromatogr 777B, 321-327.

Paolini M, Antelli A, Pozzetti L, Spetlova D, Perocco P, Valgimigli L, Pedulli GF \& Cantelli-Forti G (2001) Induction of cytochrome P450 enzymes and over-generation of oxygen radicals in beta-carotene supplemented rats. Carcinogenesis 22, $1483-1495$.

Prasad K (1997) Hydroxy radical scavenging property of secoisolariciresinol diglucoside (SDG) isolated from flaxseed. $\mathrm{Mol}$ Cell Biochem 168, 117-123.

Prasad K (1999) Reduction of serum cholesterol and hypercholesterolemic atherosclerosis in rabbits by secoisolariciresinol diglucoside isolated from flaxseed. Circulation 99, 1355-1362.

Prasad K, Mantha SV, Muir AD \& Westcott ND (1998) Reduction of hypercholesterolemic atherosclerosis by CDCflaxseed with very low alpha-linolenic acid. Atherosclerosis 136, 367-375.

Qui SX, Lu ZZ, Luyengi L, Lee SK, Pezzuto JM, Farnsworth NR, Thompson LU \& Fong HHS (1999) Isolation and characterization of flaxseed (Linum usitatissimum) constituents. Pharm Biol 37, 1-7.

Ratnayake WMN, Behrens WA, Fischer PWF, L'Abbé MR, Mongeau R \& Beare-Rogers JL (1992) Chemical and nutritional studies of flaxseed (variety Linott) in rats. J Nutr Biochem 3, 232-240.

Rickard SE \& Thompson LU (1998) Chronic exposure to secoisolariciresinol diglycoside alters lignan disposition in rats. $J$ Nutr 128, 615-623.

Seigler L \& Wu WT (1981) Separation of serum high-density lipoprotein for cholesterol determination: ultracentrifugation vs precipitation with sodium phosphotungstate and magnesium chloride. Clin Chem 27, 838-841.

Setchell KD, Lawson AM, Borriello SP, Harkness R, Gordon H, Morgan DM, Kirk DN, Adlercreatz H, Anderson LC \& Axelson M (1981) Lignan formation in man - microbial involvement and possible roles in relation to cancer. Lancet ii, 4-7.

Sicilia T, Niemeyer HB, Honig DM \& Metzler M (2003) Identification and stereochemical characterization of lignans 
in flaxseed and pumpkin seeds. J Agric Food Chem 51, $1181-1188$.

Sontag TJ \& Parker RS (2002) Cytochrome P450 omega-hydroxylase pathway of tocopherol catabolism. Novel mechanism of regulation of vitamin E status. J Biol Chem 277, 25290-25296.

Thompson LU, Seidl MM, Rickard SE, Orcheson LJ \& Fong HH (1996) Antitumorigenic effect of a mammalian lignan precursor from flaxseed. Nutr Cancer 26, 159-165.

Westcott ND \& Muir AD (1996) Process for extracting and purifiying lignans and cinnamic acid derivatives from flaxseed. PCT patent no. WO9630468A2.

Westcott ND \& Muir AD (1998) Process for extracting lignans from flaxseed. US patent no. 5.705.618.

Westcott ND \& Muir AD (2000) Overview of flax lignans. INFORM 11, 118-121.

Wright JS, Johnson ER \& DiLabio GA (2001) Predicting the activity of phenolic antioxidants: theoretical method, analysis of substituent effects, and application to major families of antioxidants. J Am Chem Soc 123, 1173-1183. 